\title{
Meinhard Robinow: An Appreciation
}

\author{
Stanley M. Garn, Thaddeus E. Kelly, and John M. Opitz \\ Center for Human Growth and Development, University of Michigan, Ann Arbor, Michigan (S.M.G.), Division of \\ Medical Genetics, University of Virginia Hospital, Charlottesville, Virginia (T.E.K.), and Foundation for \\ Developmental and Medical Genetics, Helena, and Montana State University, Bozeman, Montana (J.M.O.)
}

\section{INTRODUCTION}

At the age of 86, Meinhard Robinow (Fig. 1), still active as a clinical geneticist and passionate horticulturist, is entitled to look back on an exceptionally interesting and fruitful life with great satisfaction. What a blessing for the fields of growth analysis, syndromology, and clinical genetics in general that Meinhard did not fall a victim of Nazi persecution, but, like so many others (e.g., Josef Warkany), was accepted warmly in the New World, where he was destined to develop his great skills as a pediatric geneticist and diagnostician. What is less known in the field is that before his career in clinical genetics, Meinhard spent several very productive years in, and made substantial contributions to, the anthropometry of growth analysis at the Fels Research Institute in Yellow Springs, Ohio. Of particular importance are his three great papers of 1942: 1) Appearance of Ossification Centers, Groupings Obtained From Factor Analysis; 2) The Variability of Weight and Height Increments From Birth to Six Years; and 3) The Eruption of Deciduous Teeth. Stan Garn, his successor at the Fels Research Institute, remembers Meinhard from those years as follows:

"I first encountered the name Meinhard Robinow while writing my undergraduate thesis in the summer of 1942. Since his paper on deciduous tooth eruption was so complete and statistically sophisticated, I started to ask around to find out who Robinow was and what the Fels Research Institute did. My questions and the answers were as follows:

Q: Who is Robinow?

A: He is a dentist.

Q: What is the Fels Institute?

A: It's a soap company.

Q: Why are they interested in tooth eruption?

A: Because they make toothpaste.

"One decade later, to the month, I arrived at the Fels Institute and met Meinhard Robinow, then in private practice at the Yellow Springs Clinic after his military service. Soon Meinhard became our pediatrician, and also my physician (I was subject to childhood diseases, because I was continually exposed to children in the

Received for publication February $28,1995$.

Address reprint requests to John M. Opitz, M.D., FRB-Suite 229, 100 Neill Avenue, Helena, MT 59601. longitudinal studies at the Fels). I discovered that he was an avid horticulturist, and that he cultivated orchids in his home greenhouse and was a mycologist as well. Though Yellow Springs was tiny (pop. 2,500 in 1952), he drew problem cases and congenital malformation syndromes from a wide area with referrals from Dayton, Columbus, Cincinnati, and beyond. We had a common interest in Morquio syndrome and other genetic defects, and he published extensively on alkaline phosphatase deficiency and other subjects. On hypophosphatasia, he became mislabeled in the literature as "Robinson." He still appears in secondary citations under that incorrect name.

"Meinhard took the opportunity to spend time in Kampala, Uganda, with Dean and Jelliffe, investigating protein-calorie malnutrition (PCM), and was the first to describe the pronounced thinning of the skull in such cases-part of PCM-induced osteoporosis. He later joined Robert Blizzard in Virginia, continuing his interests in medical genetics, begun years earlier in Georgia.

"When I moved to Michigan in 1968, we continued our relationship, both interested in annualized growth increments, an interest which extended into dysmorphogenesis syndromes. One of my colleagues in North Carolina was quite amazed at the number of syndromes Meinhard had come to identify first at the Yellow Springs Clinic and later at the Children's Medical Center in Dayton.

"Though not a fitness buff, Meinhard kept himself trim by playing tennis and winning tournaments at 60 , 70 , and 80 . (He still plays tennis, but has not won a tournament in his 80 's.) Long before obesity became a general pediatric concern, he gave attention to juvenile obesity (especially in family context). Some parents preferred to blame their children's obesity on "glands,"

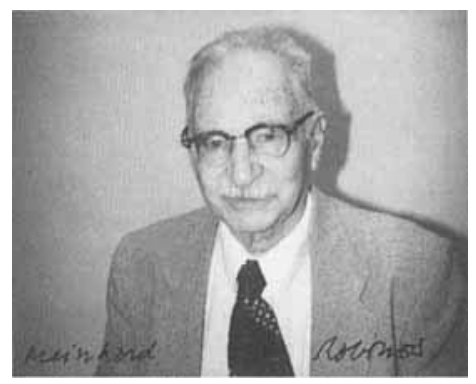

Fig. 1. Meinhard Robinow. 
unwilling to realize that they themselves were role models for obesity, and they sought thyroid medication for their obese progeny rather than dietary restriction. Meinhard lost some of those obese patients for his forthright stand.

"Meinhard inevitably viewed his patients in family context, the better to follow their growth progress. So he encouraged me to develop parent-specific height standards. He had a considerable interest in multiple allergies, and he followed allergic and asthmatic children and allergy-prone families. Meinhard was also intrigued by the problems faced by adopted children in academic families, particularly those whose intellectual progress did not match the expectations of their adoptive parents. He concluded that adoptions work better in farm families than in academic families, an observation that merits further notice."

When Robert M. Blizzard became Chairman of Pediatrics at the University of Virginia in 1974, he asked Meinhard to move to Charlottesville to develop a genetics division in the Department. He was joined a few months later by Thad Kelly, who has been a friend and co-worker for 20 years and who sent the following comments:

"Meinhard regularly attended the birth defects conferences in Baltimore and always brought an interesting case report with him. At the meetings in 1972 he described two brothers in their twenties with the clinical phenotype of pseudo-Hurler polydystrophy. As part of my efforts to study all of the known patients in the U.S. at that time, I made my first trip to Yellow Springs to visit with Meinhard and Bea. After we had seen the brothers and collected all the specimens that I needed, he introduced me to the family with the disorder he called 'fetal face syndrome.' The next week in Baltimore I saw a teenage boy with the disorder. We published a case report in which we argued for the term, Robinow syndrome, as being more acceptable for use with families. It would take about 10 years before Meinhard, with some timidity, but obvious pride, would use that term.

"At a time and age when his colleagues were retiring from their group practice in Yellow Springs, Meinhard Robinow undertook a new career. In 1975, we both moved to Charlottesville to start up a Division of Medical Genetics at the University of Virginia. Bob Blizzard left specific titles and relationships rather vague. After years as an independent, and the only, clinical geneticist in Dayton, Ohio, Meinhard was not sure he wanted to share clinical responsibilities with me. When I described a patient whom I had seen and planned to publish he was a little miffed; he never wanted to miss a possible case report. He said, 'Why don't you run the labs and leave the patients to me?' Fortunately, the clinical load was large enough to require both our attentions.

"Very soon after we were settled in, we set up a satellite clinic system serving southeast West Virginia and the western half of Virginia. Both of us went to these clinics which were held monthly, several hours' drive from Charlottesville. We were soon joined by our first genetic counselor, Pat Schnatterly. Pat's enthusiasm for the clinics, her wealth of knowledge in genetics, and her professional manner with families quickly won Meinhard over, and he became a staunch supporter of the role of genetic counselors. The three of us quickly learned our Virginia geography, often as a result of fol- lowing one of Meinhard's rules: 'Always take a different route on the return trip.' On these trips we sometimes had pediatric residents or medical students traveling with us. The first full summer of these clinics, 1976, we were accompanied by two male students who prided themselves in their athletic prowess. At our first overnight stop, we had time for tennis before dinner. The students were wondering which of them would get which of us as a partner. I suggested that Meinhard and I play as partners; he suggested that the match be for beer that evening. Those two students bought all the beer that summer, and Meinhard never let them forget that all summer they never won a set. Meinhard has a pacemaker now, so the last time we played we took a little longer than usual in changing courts between games. He has a new partner, a grandson, and they make quite a pair.

"I have always thought that if Reader's Digest ever asked me to write one of those articles about the most unforgettable character I have known,' it would be easy to decide whom to choose.

"In all the time we traveled and worked together, I never ceased to be amazed by the depth and breadth of Meinhard's knowledge. In the fall months we would often have our wives travel with us through the Blue Ridge Mountains to our clinics. Meinhard knew the name of every bush, flower, tree, or bird that we saw. We used him like an encyclopedia. A bit of folklore has sprung up about his knowledge of biology. In central Ohio, he is known as the local mushroom expert. People from a wide area brought mushrooms for his inspection before eating. I once asked him if he had ever had mushrooms brought to him that he could not identify. He acknowledged that that had happened once or twice. 'What did you tell the people?' I asked. Before he could reply, his wife, Bea, related two episodes: when faced with unknown mushrooms, Meinhard gave them the Robinow test; he ate them. Both times he ended up in the emergency room with anaphylaxis. The version of the story told by Meinhard himself is equally charming: 'A friend brought me some [unfamiliar] mushrooms. My mushroom book listed them as a "species that cannot not be mistaken for any poisonous one!" My friend asked, "Shall I eat them?" I replied, "Let me try them first!" I had scrambled eggs and mushrooms for lunch. Very tasty, but soon followed by 3 hours of nausea, vomiting, and diarrhea... When I felt quite exhausted, my 4- or 5-year-old son came into my room and asked, "Can I have my allowance? You may not be alive tomorrow."' (Fig. 2)

"My wife Carolyn and I have learned to visit the Robinows in mid-to-late summer in Ohio. They live on a large farm between Yellow Springs and Xenia. Most of the heavy-duty farming is done by a man who lives on another of their farms and manages the land. Nonetheless, the Robinows have fruit trees, flowers, and vegetables sufficient for several families. Meinhard insists, and I have seen the proof, that he does not like to spend much time weeding, pruning, spraying, etc. (all the things that take my free time during the summer). Yet, there is always a bountiful harvest that leaves me envious of his magic touch. We usually leave with cuttings for new flowers and bushes, and lots of fruit and vegetables.

"Our time on the road to clinics provided opportunities for conversations on a wide range of topics. Politics 


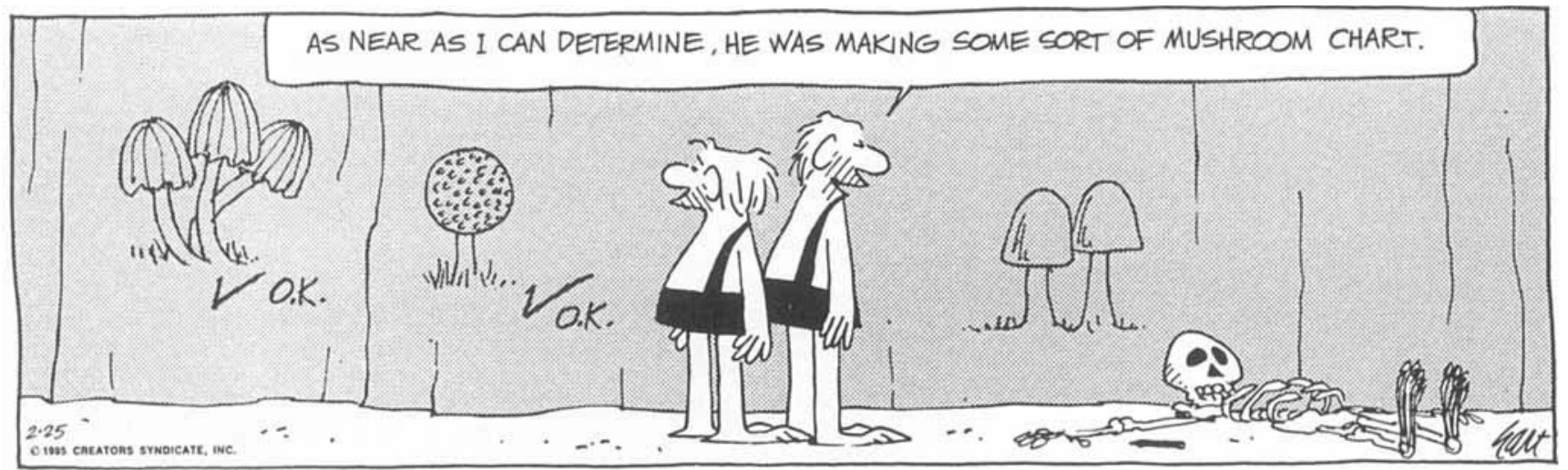

Fig. 2. The ultimate mushroom story. By permission of Johnny Hart and Creators Syndicate, Inc.

was always of interest, and we found ourselves usually in agreement and generally left of center, a position somewhat surprising considering that I grew up in rural South Carolina to become a 'yellow dog' democrat and Meinhard left the family home in Hamburg in the 1930 's. He was a liberal and a liberated man. He disliked family dynasties based on wealth, he was eager to see disadvantaged individuals do well, and he was very aware of his responsibilities as a voter. However, after 50 years in the United States he has still not mastered the 'ths' sound, as in months.

"It has been 15 years since he left the University of Virginia and returned to his Ohio farm. He loved to point out that the Department had to hire two people to do the work he had done alone. He has continued a small private practice and regularly attends the David

TABLE I. Contributions of Meinhard Robinow to Mendelian Syndrome Definition and Delineation 1943-1995, as Listed in McKusick (1994)*

\begin{tabular}{|c|c|c|}
\hline McKusick \# & Entity & Robinow publications \\
\hline 101600 & Acrocephalosyndactyly, type V & $57(1975)$ \\
\hline 101800 & Acrodysostosis & $43(1971)$ \\
\hline 103300 & Aglossia-adactylia (Hanhart) & $65,67(1978)$ \\
\hline 108760 & Atresia of external auditory canal and conductive deafness & $73(1979)$ \\
\hline 112350 & Bowing of legs, anterior, with dwarfism (Weismann-Netter syndrome) & $\begin{array}{l}124(1988) ; 134,138 \\
\quad(1990)\end{array}$ \\
\hline 114300 & Camptodactyly, cleft palate, and clubfoot (Gordon syndrome) & $78(1981)$ \\
\hline 119300 & Cleft lip and/or palate with mucous cysts of lower lip (Van der Woude syndrome) & $74(1980)$ \\
\hline 120000 & Coarctation of aorta & $108(1985)$ \\
\hline 151050 & Lenz-Majewski hyperostotic dwarfism & $\begin{array}{l}63(1977) ; 121(1987) ; 126 \\
\quad 136(1990)\end{array}$ \\
\hline 153400 & Lymphedema with distichiasis & $\begin{array}{l}37(1968) ; 41(1970) ; 85 \\
\quad(1982)\end{array}$ \\
\hline 158310 & Mucoepithelial dysplasia, hereditary & $117(1987) ; 139(1991)$ \\
\hline 172880 & $\begin{array}{l}\text { Pierre Robin syndrome and oligodactyly (actually a contribution to postaxial } \\
\text { acrofacial dysostosis (Genée-Wiedemann) }\end{array}$ & $\begin{array}{l}111(1986) ; 120(1987) \\
133(1990)\end{array}$ \\
\hline 180700 & Robinow dwarfism & $\begin{array}{l}38,40(1969) ; 48,51 \\
\quad(1973) ; 70(1979) ; 83,86 \\
(1982) ; 113,116(1986) ; \\
122(1988) ; 132,135 \\
(1990) ; 144(1993)\end{array}$ \\
\hline 180750 & Robinow-Sorauf syndrome (q.v. 101600 above) & $57(1975)$ \\
\hline 186300 & Syndactyly, type V & $87(1982)$ \\
\hline 213002 & Cerebellar hypoplasia with endosteal sclerosis & $142(1991)$ \\
\hline 219250 & Cutis marmorata telangiectatica congenita (CMTC) & Personal communication \\
\hline 234100 & Hallermann-Streiff syndrome & $140(1991)$ \\
\hline 236670 & Hydrocephalus, agyria, and retinal dysplasia (Walker-Warburg syndrome) & $114(1986) ; 125(1989)$ \\
\hline 236700 & $\begin{array}{l}\text { Hydrometrocolpos, postaxial polydactyly, and congenital heart malformation } \\
\text { (Kaufman-McKusick syndrome) }\end{array}$ & $72(1979)$ \\
\hline 252600 & Mucolipidosis III & $50,53(1974) ; 59(1975)$ \\
\hline 253280 & Muscle-eye-brain disease (MEB disease) & $125(1989)$ \\
\hline 259770 & Osteoporosis-pseudoglioma syndrome & $106(1985)$ \\
\hline 268310 & Robinow syndrome, AR & $118(1987) ; 122(1988)$ \\
\hline 271100 & Spinal extradural cyst (q.v. 153400) & $41(1970)$ \\
\hline 277610 & Weissenbacher-Zweymuller syndrome & $61(1975)$ \\
\hline 304050 & Corpus callosum, agenesis of, with chorioretinal abnormality (Aicardi syndrome) & $98(1984)$ \\
\hline
\end{tabular}

\footnotetext{
* Twenty-three of the above references are not cited in McKusick, but were added from Robinow's bibliography.
} 
TABLE II. Contributions of Meinhard Robinow to Mendelian Syndrome Definition and Delineation 1943-1995, Not Listed in McKusick Catalogues*

\begin{tabular}{|c|c|c|}
\hline Entity & Paper \# & Year \\
\hline Hemophilia A & 20 & 1943 \\
\hline Morquio disease & 23 & 1958 \\
\hline Vasopressin-resistant diabetes insipidus & 29 & 1962 \\
\hline Hyperlysinemia & 35 & 1967 \\
\hline Phenylketonuria (PKU) & 45 & 1970 \\
\hline \multirow[t]{3}{*}{ Muscular dystrophy, Duchenne } & 62 & 1975 \\
\hline & 81 & 1982 \\
\hline & 96 & 1983 \\
\hline Zellweger syndrome & 60 & 1975 \\
\hline Hereditary sclerosing poikiloderma & 66 & 1978 \\
\hline Cerebral gigantism & 75 & 1980 \\
\hline Wiedemann-Beckwith syndrome & 80 & 1981 \\
\hline Riley-Smith macrocephaly-angiomatosis & 85 & 1982 \\
\hline Pfeiffer syndrome & 102 & 1984 \\
\hline \multirow[t]{2}{*}{ Syndrome of osteopathia striata, macrocephaly, and cranial sclerosis } & 103 & 1984 \\
\hline & 137 & 1990 \\
\hline Costal dysgenesis and male pseudohermaphroditism - a new syndrome? & 104 & 1984 \\
\hline Hemifacial microsomia. ... & 110 & 1986 \\
\hline Ectrodactyly and absence of long bones of upper and lower limbs, AD & 119 & 1987 \\
\hline Sacrococcygeal dysgenesis and associated congenital anomalies & 143 & 1991 \\
\hline Goldenhar syndrome & 145 & 1993 \\
\hline
\end{tabular}

Smith Dysmorphology Conferences. We see each other regularly and each time we meet, he is eager to describe a current case report he is working on. Oh, were it possible to light a similar fire to publish in the minds of new fellows. His bibliography is outstanding by any measure; it is even more so when one realizes that the bulk of this work was accomplished during a time when he was a primary care pediatrician interested in birth defects, but far removed from an academic center. Today, students often seem to be interested only in the material on which they will be tested in an examination; the love of learning seems to have lost out to the sheer competition for a better grade. These students need role models such as Meinhard Robinow, for whom learning for learning's sake has been a lifelong pursuit. One can only hope that our system of health care delivery will never become so limited in its perspective that people such as Meinhard Robinow will not have the opportunity to grow and flourish in their practice."

Robinow's bibliography is indeed impressive, and Table I summarizes some of the entities on which he has worked and which are cited by McKusick [1994]. Table II summarizes contributions not listed in the McKusick Catalogues. There are 28 citations of his work in the 11th edition of McKusick's Catalogue, curiously not for hypophosphatasia, adult type (\#146300), which he discovered, as he recounts in his Living History-Autobiography [Robinow, 1995], in a 19-monthold girl whom he first evaluated in his office in 1950 [see Sobel et al., 1953].

Meinhard is probably best known for his discovery of the autosomal-dominant form of Robinow syndrome (\#180700), on which he has contributed several important publications and reviews. He also recognized early that the condition is heterogeneous, with an almost equally substantial literature now published on the autosomal-recessive form of Robinow syndrome (\#268310) as on the dominant form.
Less well-known is the Robinow-Sorauf syndrome (\#180750), first described by these authors as a form (Noack) of acrocephalosyndactyly, and recognized as a distinct syndrome by Carter et al. [1982] (who coined the eponym), and by Young and Harper [1982]. Lenz and Majewski [1991] have some reservations about the independent nosologic nature of this entity and think that separation from the Saethre-Chotzen syndrome is premature. In 1977, Robinow, working with Johanson and Smith in Charlottesville, coined the eponym LenzMajewski syndrome for a form of hyperostotic dwarfism, mental retardation, and proximal symphalangism (\#151050) which they had studied.

It is a reflection of a basic humility to refer to oneself as an "amateur" after having made so many recognized, substantial contributions to the field of clinical genetics. What is most admirable about the life of Meinhard Robinow is that this professional humility is coupled with an evident love of life, an infectious enthusiasm, and a devotion to hard work, which allowed him to make contributions of such importance that the name Robinow shall not perish from the annals of clinical genetics.

\section{ACKNOWLEDGMENTS}

We are most grateful for the expert secretarial collaboration of Mrs. Yvonne Stevenson, and the editorial assistance of LaVelle M. Spano.

\section{REFERENCES}

Lenz W. Majewski F (1991): Fehlbildungen der Gliedmaßen. In Schinz: "Radiologische Diagnostik in Klinik und Praxis," Vol. VI, Part 2 (7th ed.). Stuttgart, New York: Georg Thieme Verlag, pp 935-1032.

McKusick VA (1994): "Mendelian Inheritance in Man-A Catalog of Human Genes and Genetic Disorders," 11th ed. Baltimore: The Johns Hopkins University Press.

Robinow M (1995): Living history-autobiography: Pediatric genetics in a new world. Am J Med Genet 59: 8-13.

Sobel E, Clark L, Fox P, Robinow M (1953): Cincinnati Yellow Springs. Pediatrics 11:309-321. 